\title{
Detection of cytokeratin- 19 mRNA-positive cells in the peripheral blood and bone marrow of patients with operable breast cancer
}

\author{
A Daskalaki',2,4, S Agelaki ${ }^{2,3,4}$, M Perraki ${ }^{2}$, S Apostolaki ${ }^{2}$, N Xenidis ${ }^{3}$, E Stathopoulos', E Kontopodis ${ }^{3}$, \\ D Hatzidaki ${ }^{3}$, D Mavroudis ${ }^{2,3}$ and V Georgoulias*,2,3
}

'Department of Pathology, University General Hospital of Heraklion, Crete, Greece; ${ }^{2}$ Laboratory of Tumor Cell Biology, School of Medicine, University of Crete, Heraklion, Greece; ${ }^{3}$ Department of Medical Oncology, University Hospital of Heraklion, Crete, Greece

\begin{abstract}
BACKGROUND: To compare detection rates and evaluate the clinical relevance of cytokeratin-19 (CK-19) mRNA-positive cells in the peripheral blood (circulating tumour cells, CTCs) and bone marrow (disseminated tumour cells; DTCs) of patients with early breast cancer.

METHODS: Paired samples of peripheral blood and bone marrow were obtained from 165 patients with stage I- II breast cancer before the initiation of adjuvant chemotherapy. In 84 patients, paired blood and bone marrow samples were also available after chemotherapy. The detection of CK-19 mRNA-positive CTCs and DTCs was assessed by real-time PCR.

RESULTS: CK-19 mRNA-positive CTCs and DTCs were detected in 55.2 and $57.6 \%$ of patients before chemotherapy, respectively. After chemotherapy, CTCs and DTCs were identified in 44 (52.4\%) and 43 (51.2\%) of the 84 patients, respectively. There was a 93.9\% (McNemar; $P=0.344)$ and 72.6\% (McNemar; $P=0.999)$ concordance between blood and bone marrow samples before and after chemotherapy, respectively. The detection of CK-19 mRNA-positive CTCs or DTCs before chemotherapy was associated with decreased overall survival $(P=0.024$ and $P=0.015$, respectively). In addition, their simultaneous detection was also associated with an increased incidence of disease-related death and decreased overall survival $(P=0.016)$.

CONCLUSIONS: The detection of CK-19 mRNA-positive CTCs using reverse transcription-PCR (RT-PCR) both before and after chemotherapy is correlated with the detection of CK-19 mRNA-positive DTCs in patients with early-stage breast cancer. The determination of the CTC status by RT-PCR conveys clinically relevant information that is not inferior to DTC status and, owing to the ease of sampling, warrants further evaluation as a tool for monitoring minimal residual disease.

British Journal of Cancer (2009) I 0 I, 589-597. doi:I0.I038/sj.bjc.6605 I 83 www.bjcancer.com
\end{abstract}

Published online 2I July 2009

(c) 2009 Cancer Research UK

Keywords: breast cancer; circulating tumour cells; CK-19; micrometastasis; disseminated tumour cells

Although adjuvant chemotherapy and hormone treatment have improved disease-free and overall survival (OS) (EBCTC Group, 2005 ), almost $30 \%$ of patients with node-negative breast cancer will present distant metastases and will die as a result of disseminated disease (EBCTC Group, 1998). This is due to early tumour-cell dissemination through the lymphatic or the hematogenous vasculature (Dowlatshahi et al, 1997; Giatromanolaki et al, 2004; Stathopoulos et al, 2005). Indeed, epithelial tumour cells can be identified in bone marrow aspirates (disseminated tumour cells, DTCs) or in the peripheral blood (circulating tumour cells, CTCs) of otherwise metastases-free breast cancer patients using either immunohistochemical or molecular assays (Schoenfeld et al, 1997; Pantel et al, 1999; Slade et al, 1999).

The immunocytochemical detection of DTCs has been shown to be associated with decreased disease-free survival (DFS) and OS of patients with operable breast cancer (Mansi et al, 1999; Braun et al,

\footnotetext{
*Correspondence: Professor $\vee$ Georgoulias, Department of Medical Oncology, University Hospital of Heraklion, PO Box 1352, Heraklion, Crete 7III0, Greece; E-mail: georgsec@med.uoc.gr

${ }^{4}$ These authors contributed equally to this work.

Received 7 January 2009; revised 3 June 2009; accepted 12 June 2009; published online 2I July 2009
}

2000b; Wiedswang et al, 2003; Braun and Naume, 2005). We have reported earlier that the detection of CTCs before the initiation of adjuvant chemotherapy in patients with operable breast cancer, irrespective of the presence of axillary lymph node involvement (Stathopoulou et al, 2002; Wiedswang et al, 2003; Xenidis et al, 2006), or an oestrogen/progesterone or HER2 receptor expression (Ignatiadis et al, 2007), is also an independent factor associated with decreased DFS and OS.

The detection of DTCs and CTCs during both adjuvant and metastatic settings could be a useful tool for monitoring the efficacy of systemic treatment. It has been reported that adjuvant chemotherapy may eliminate DTCs (Braun et al, 2000a) or CTCs (Xenidis et al, 2003) in only $50 \%$ of patients. Moreover, the detection of CTCs during the administration of adjuvant tamoxifen is associated with decreased DFS and OS (Xenidis et al, 2007). Finally, Cristofanilli et al (2004) showed that the decrease in the absolute number of CTCs during chemotherapy in patients with metastatic breast cancer could be considered as an early event, indicating the efficacy of treatment. However, in patients with early breast cancer, who are asymptomatic, repeated and frequent bone marrow aspirations for the detection of DTCs may not be easily acceptable. Conversely, the use of blood for detecting CTCs is more convenient and could be easily acceptable by patients, thus 
representing a valuable alternative solution. Although some previous studies (Ismail et al, 2004; Pierga et al, 2004; Muller et al, 2005; Benoy et al, 2006; Wiedswang et al, 2006) have shown a correlation between the detection of DTCs and CTCs, this fact has not been unanimously accepted. This could be due to the fact that in most studies, the comparison of the detection of CTCs and DTCs was carried out using immunocytochemical assays, which, in general, have a lower sensitivity compared with molecular assays.

The main objective of this study was the direct comparison of the detection rate of cytokeratin-19 (CK-19) mRNA-positive CTCs and DTCs in paired samples of the peripheral blood and bone marrow obtained from patients with early breast cancer. The secondary objective was the evaluation of their prognostic significance in the same group of patients hypothesising that peripheral blood sampling could replace bone marrow aspiration as a prognostic tool in patients with early breast cancer.

\section{PATIENTS AND METHODS}

\section{Patients}

A study evaluating the clinical relevance of CK-19 mRNA-positive CTCs and/or DTCs in patients with early stage or metastatic breast cancer has been underway since 1996 at the Department of Medical Oncology at the University Hospital of Heraklion (Crete, Greece). Peripheral blood or bone marrow aspirates are obtained from patients who sign an informed consent, before the initiation of adjuvant or front-line treatment as part of their initial evaluation. In this study, we retrospectively identified a total of 165 patients who had all undergone adjuvant chemotherapy for stage I-II breast cancer from March 1999 to January 2004, and for whom paired blood and bone marrow samples before the initiation of any systemic treatment were available. In $162(98.2 \%)$ of them, a blood sample was also available after the completion of treatment, whereas only $84(50.9 \%)$ consented for a repeated bone marrow aspiration after adjuvant chemotherapy.

Every enrolled patient underwent a complete baseline diagnostic evaluation to exclude distant metastases before primary surgery, which consisted of chest X-rays, mammography, abdominal ultrasound and whole-body bone scan. Further imaging studies (computed tomography scans and magnetic resonance imaging) were carried out, if clinically indicated. Surgical treatment was either mastectomy or lumpectomy with axillary lymph node dissection. Radiation treatment was given to patients who underwent lumpectomy and to those with four or more axillary lymph nodes. All patients included in this study underwent adjuvant chemotherapy and most were treated in the context of research protocols of the Hellenic Oncology Research Group (HORG). Adjuvant chemotherapy consisted of either FEC (Fluoruracil, Epirubicin, Cyclophosphamide) or EC/T (Epirubicin, Cyclophosphamide/Taxotere), or classical CMF (Cyclophosphamide, Methotrexate, Fluoruracil) (details of the used chemotherapy regimens have been previously reported; Ignatiadis et al, 2007). Patients with HER2-positive tumours were not given adjuvant trastuzumab, because all were treated before the positive results from the adjuvant trastuzumab trials were reported. Patients with oestrogen receptor (ER)-positive and/or progesterone receptor (PR)-positive tumours were given $20 \mathrm{mg}$ tamoxifen daily for 5 years; pre-menopausal women were also given luteinising hormone-releasing hormone analogues for 2 years.

Follow-up was conducted every 3 months during the first 2 years, every 6 months until 5 years after surgery and yearly thereafter, and it consisted of a clinical examination with routine laboratory studies (including tumour markers) and imaging studies with X-rays and abdominal ultrasound (computed tomography scans and magnetic resonance imaging were carried out, if clinically indicated). The administration of adjuvant chemotherapy and hormonal treatment was decided independently of the molecular detection of CTCs or
DTCs. Moreover, during the follow-up period, clinicians were blinded for the results of CK-19 mRNA detection.

\section{Clinical samples}

Peripheral blood (20 $\mathrm{ml}$ in EDTA) and bone marrow aspirations $(3 \mathrm{ml}$ in EDTA aspirated from the posterior iliac crest under local anaesthesia) were obtained before the initiation of adjuvant treatment (usually 3 or 4 weeks after primary surgery). Peripheral blood and bone marrow aspirates were also obtained after the completion of adjuvant chemotherapy from patients who gave their consent. All blood samples were obtained from vein puncture after the first $5 \mathrm{ml}$ of blood was discarded; similarly, the initial $0.1-0.2 \mathrm{ml}$ of bone marrow aspirate was discarded. This precaution was undertaken to avoid a contamination of the blood or bone marrow samples with epithelial cells from the skin during sample collection.

\section{RNA extraction and real-time PCR assay for CK-19 mRNA-positive cells}

For this study, frozen RNA samples stored in the biobank of the laboratory of Tumour Cell Biology were used. Both peripheral blood and bone marrow samples had been processed for mononuclear cell isolation in room temperature within $2-4 \mathrm{~h}$ after sampling. Briefly, samples were diluted (vol/vol) with RNase-free, sterile $0.9 \% \mathrm{NaCl}$, and mononuclear cells (peripheral blood mononuclear cells and bone marrow mononuclear cells, respectively) were obtained by Ficoll-Hypaque (Sigma-Aldrich, St Louis, MO, USA) gradient density centrifugation at $1200 \mathrm{~g}$ for $30 \mathrm{~min}$ at $4{ }^{\circ} \mathrm{C}$. Interface cells were obtained, washed twice with sterile phosphate-buffered saline and stored at $-80{ }^{\circ} \mathrm{C}$ until use. Total RNA isolation was carried out using Trizol LS reagent (Gibco Life Sciences, BRL, Grand Island, NY, USA), according to the manufacturer's instructions. All RNA preparations and handling steps were conducted in a laminar flow hood, under RNAse-free conditions. Isolated RNA was dissolved in diethylpyrocarbonatetreated water and stored at $-80{ }^{\circ} \mathrm{C}$ until use. RNA concentration was determined by absorbance reading at $260 \mathrm{~nm}$ using the Hitachi UV-VIS (U-2000) spectrophotometer (Tokyo, Japan). RNA integrity was tested by PCR amplification of the $\beta$-actin housekeeping gene. RNA isolated from MCF-7 breast cancer and the ARH-77 leukaemic cell lines was used as positive and negative controls, respectively.

Reverse transcription of RNA was carried out using the Thermoscript RT-PCR system (Invitrogen, Paisley, UK). cDNA was synthesised according to the manufacturer's instructions. The real-time RT-PCR assay for the detection of CK-19 mRNApositive cells has already been described in detail (Stathopoulou et al, 2003). In brief, $2 \mu \mathrm{l}$ of cDNA was placed into $18 \mu \mathrm{l}$ of reaction volume containing $1 \mu \mathrm{l}$ of the sense primer CK-19-for $\left(3 \mathrm{mmoll}^{-1}\right)$, $1 \mu \mathrm{l}$ of the anti-sense primer CK-19-do $\left(3 \mathrm{mmoll}^{-1}\right), 2.4 \mu \mathrm{l}$ of the LightCycler-FastStart DNA Master Hybridization probes reagent (Roche, Mannheim, Germany) ( $10 \times$ concentration), $1 \mu \mathrm{l}$ of the probe CK-19-FL $\left(3 \mathrm{mmol}^{-1}\right)$, and $1 \mu \mathrm{l}$ of the probe CK-19-LC $\left(3 \mathrm{mmoll}^{-1}\right)$. The primers used have been described earlier (Stathopoulou et al, 2003). PCR was initiated with a 10-min denaturation at $95{ }^{\circ} \mathrm{C}$ and terminated with a 30 -s cooling step at $40{ }^{\circ} \mathrm{C}$. The cycling protocol consisted of a denaturation step at $95^{\circ} \mathrm{C}$, annealing at $60^{\circ} \mathrm{C}$ for $10 \mathrm{~s}$, and extension at $72^{\circ} \mathrm{C}$, and repeated 50 times. Fluorescence detection was performed at the end of each annealing step for $<1 \mathrm{~s}$. Real-time PCR for the housekeeping gene GAPDH was performed in all of the clinical samples to evaluate the quality of the cDNAs used in the study. The lower detection limit of the assay was set at 0.6 MCF-7 cell equivalents per $5 \mu \mathrm{g}$ of RNA (Stathopoulou et al, 2003). The within-run curve values (CVs) for MCF-7 cells as determined by the calibration curve ranged from 7.5 to $9.3 \%$, whereas the corresponding crossing point $(\mathrm{Cp})$ values ranged from 0.9 to $1.5 \%$; 
similarly, the between-run CVs ranged from 10.7 to $16.0 \%$, whereas the corresponding $C \mathrm{p}$ values ranged from 2.2 to $3.2 \%$. According to the analytic detection limit of our assay, the presence of $\geqslant 0.6$ MCF-7 equivalents per $5 \mu \mathrm{g}$ of total RNA derived from peripheral blood mononuclear cells was considered as a positive result (Stathopoulou et al, 2003). Using the above cutoff values, only 2 out of 89 healthy female donors were positive (2.2\%) (Stathopoulou et al, 2003). Furthermore, none of the nine women with benign breast disease had positive blood samples. Twenty-seven bone marrow aspirates from normal donors $(n=7)$ or patients with non-epithelial $(n=5)$ or haematological malignancy $(n=15)$ served as controls for the determination of the cutoff point for CK-19 mRNA expression in the bone marrow. The cutoff value, based on the 95th percentile of the CK-19 mRNA values of controls, was 0.6 MCF-7 equivalents per $5 \mu \mathrm{g}$ of total RNA.

\section{Study design}

This is a retrospective analysis of prospectively collected data in the context of an ongoing longitudinal study. The aim of this study was to evaluate the detection rate and the prognostic relevance of the presence of CTCs and DTCs in patients with early breast cancer (McShane et al, 2005). Patients were enrolled during the period from March 1999 to January 2004. All patients signed an informed consent, which was approved by the Ethics and Scientific Committees of our Institution. As of June 2008, median followup time was 59.0 months (range, 13-95). Survival intervals were calculated from the first dose of chemotherapy until the date of death or of the first clinical or imaging evidence of disease recurrence.

\section{Statistical analysis}

Differences of rates between groups were compared with either the two-sided Fisher's exact test or Pearson's $\chi^{2}$-test. Differences between groups in terms of continuous variables were assessed by the non-parametric Mann-Whitney test. The normality of continuous variables was verified using the Kolmogorov-Smirnov test. The Spearman exact test was performed to evaluate the correlation between the expression of CK-19 mRNA cells in the peripheral blood and bone marrow (Cox, 1970; Collett, 2003).

Differences in positivity rates between blood and bone marrow samples were assessed using the McNemar test. The Kaplan-Meier method was used to estimate DFS and survival curves, and the logrank test was used to compare the curves (Altman, 1991; Armitage and Berry, 1994). The Cox proportional hazards model (Armitage and Berry, 1994) was used for outcomes related to time-to-event data and prognostic values. In order to construct such a model using covariates that have an independent significant influence on outcomes, a stepwise procedure (unconditional backward) was carried out (Armitage and Berry, 1994). Before the application of these methods, univariate analysis was performed for the preliminary exploration of variables of interest. $P$-values $<0.05$ were considered statistically significant for all comparisons.

\section{RESULTS}

\section{Patient characteristics}

Patient characteristics are listed in Table 1. Patients' median age was 54 years (range, 26-75 years), 78 (47.3\%) were pre-menopausal, (111) $91.5 \%$ had tumours $>2 \mathrm{~cm}, 64(38.8 \%)$ were of histological grade 3, 64 (38.8\%) were ER negative, 33 (20\%) were HER2 positive, and 106 (64.3) had infiltrated axillary lymph nodes.

\section{Detection of CTCs and DTCs before the initiation of adjuvant treatment}

CK-19 mRNA-positive CTCs and DTCs were detected in 91 $(55.2 \%)$ and $95(57.6 \%)$ of 165 patients, respectively. No correlation was found between the detection of CK-19 mRNApositive CTCs or DTCs and the patients' clinical or pathological characteristics (Table 1). The median number of CTCs and DTCs was 2.0 (range, 0.6-149) and 2.0 (range, 0.6-732) MCF-7 equivalents per $5 \mu \mathrm{g}$ RNA, respectively $(P=0.743)$. A strong correlation was observed between the detection of CK-19 mRNApositive cells in peripheral blood and in bone marrow (Spearman test, $R \mathrm{~s}=0.750 ; P=0.0001$; Figure $1 \mathrm{~A}$ ).

As indicated in Table 2, $88(53.3 \%)$ patients with detectable DTCs also had detectable CTCs (DTC $(+) / C T C(+)$ group); in addition, in $67(40.6 \%)$ patients, no occult tumour cells could be detected either in the bone marrow or peripheral blood (DTC $(-)$ / CTC(-) group). In $3(1.8 \%)$ patients with detectable CTCs, no DTCs were detected (DTC $(-) / C T C(+)$ group), whereas in 7 (4.2\%) patients with DTCs, no CTCs were detected (DTC $(+) /$ CTC(-) group). Overall, there was $93.9 \%$ concordance (in 155 out of 165 patients) for the presence of occult tumour cells between peripheral blood and bone marrow, before the initiation of adjuvant chemotherapy. According to the McNemar test, the difference in positivity rates between the peripheral blood and bone marrow CK-19 mRNA expression was not statistically significant $(P=0.344)$.

\section{Detection of CTCs and DTCs after the completion of adjuvant chemotherapy}

In 162 patients, repeated blood samples were available after the completion of adjuvant chemotherapy. The CK-19 mRNA expression was evident in $79(48.8 \%)$ patients compared with $90(55.6 \%)$ patients before chemotherapy $(P=0.169)$. Of 91 patients with detectable CK-19 mRNA-positive CTCs before chemotherapy, 58 (63.7\%) remained positive and 32 (35.2\%) were negative for CK-19 mRNA expression after chemotherapy (no data available for 1 patient). The median number of CTCs identified after chemotherapy was 1.3 (range, 0.6-25.0) equivalents per $5 \mu \mathrm{g}$ of RNA, which was not significantly different compared with pre-chemotherapy values $(P=0.341)$. Conversely, $21(28.4 \%)$ of 74 patients without detectable CK-19 mRNA-positive CTCs before chemotherapy became CK-19 mRNA positive after chemotherapy.

In the group of 84 patients with repeated bone marrow samples available after chemotherapy, 43 (51.2\%) had CK-19 mRNApositive DTCs compared with $53(63.1 \%)$ patients before chemotherapy $(P=0.099)$. In $33(62.2 \%)$ of 53 initially DTC $(+)$ patients, occult tumour cells persisted, whereas in 20 (37.7\%), no tumour cells could be identified after chemotherapy. The median number of DTCs identified after chemotherapy was 1.0 MCF-7 cell equivalents per $5 \mu \mathrm{g}$ of RNA (range 0.6-87), which was significantly different compared with pre-chemotherapy values $(P=0.045)$. Conversely, among $31 \mathrm{DTC}(-)$ patients before chemotherapy, 10 (32.2\%) had CK-19 mRNA-positive CTCs identified after chemotherapy.

A strong correlation was observed between the presence of CK19 mRNA-positive CTCs and DTCs after chemotherapy (Spearman test, $R s=0,696 ; P=0.0001$, Figure $1 \mathrm{~B})$. Indeed, as indicated in Table 2, $44(52.4 \%)$ out of 84 patients had detectable CTCs in peripheral blood after chemotherapy. A total of $32(38.1 \%)$ patients with detectable DTCs also had detectable CTCs and 29 (34.5\%) patients with a CK-19 mRNA-negative bone marrow also presented with a CK-19 mRNA-negative peripheral blood sample. The concordance rate for the bone marrow and peripheral blood CK-19 mRNA expression after the completion of adjuvant chemotherapy was $72.6 \%$. According to the McNemar test, the difference 
Table I Patients' characteristics

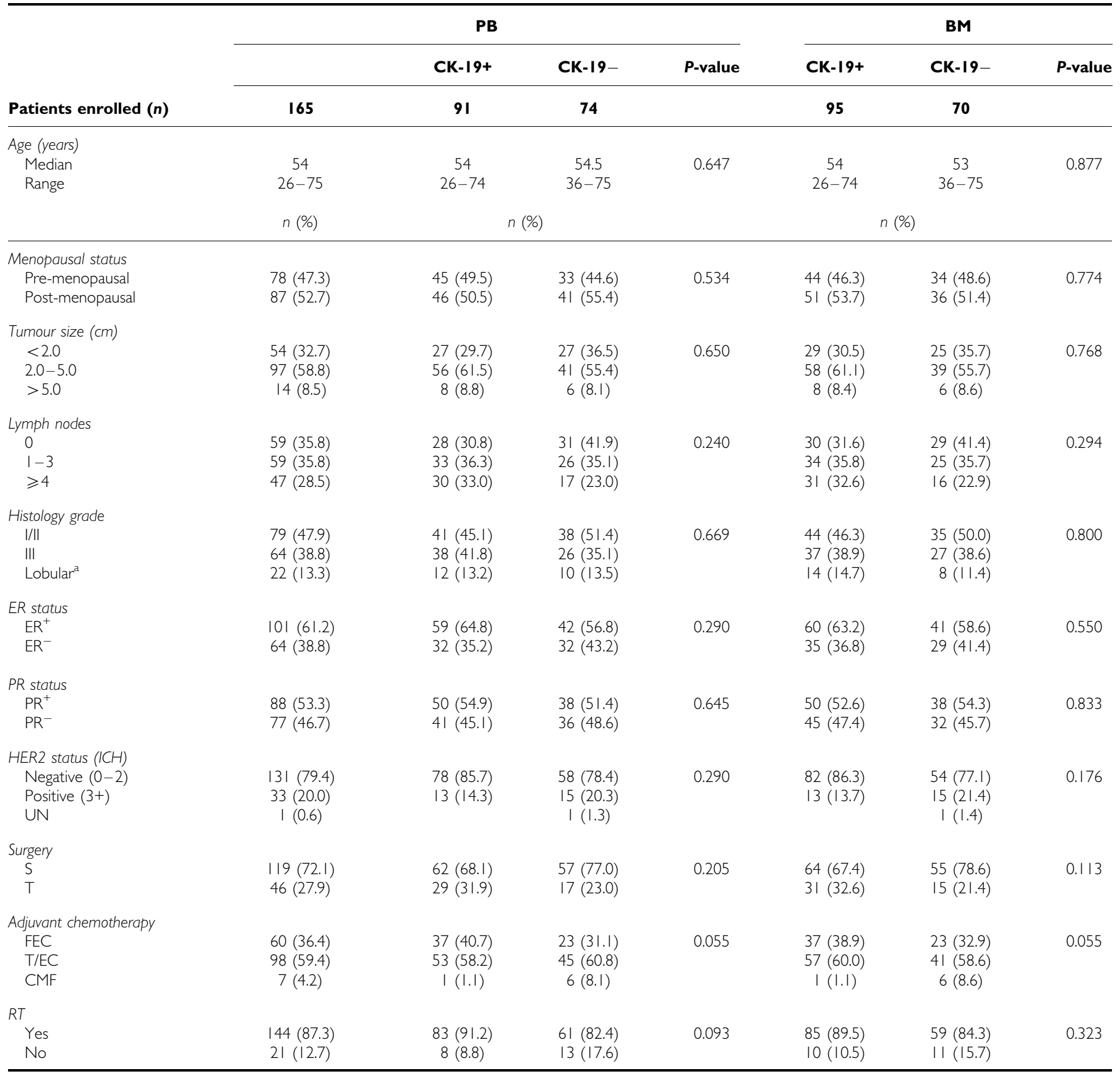

$\mathrm{BM}=$ bone marrow; $\mathrm{CK}-19=$ cytokeratin-19; $\mathrm{ER}=$ oestrogen receptor; $\mathrm{PR}=$ progesterone receptor; $\mathrm{PB}=$ peripheral blood; $\mathrm{RT}=$ radiotherapy; $\mathrm{S}=$ segmentectomy/ lumpectomy; $\mathrm{T}=$ total radical mastectomy; $\mathrm{UN}=$ unknown. a Lobular carcinomas $(n=22)$ are not scored by histological grade.

in positivity rates between the blood and bone marrow CK-19 mRNA expression was not statistically significant $(P=0.999)$.

With regard to the concomitant detection of tumour cells in the peripheral blood and bone marrow in the same group of 84 patients, $9(18.4 \%)$ of the $49 \mathrm{DTC}(+) / \mathrm{CTC}(+)$ patients before chemotherapy were found negative in both peripheral blood and bone marrow, whereas $4(13.7 \%)$ of 29 patients who were initially DTC $(-) / \mathrm{CTC}(-)$ became DTC $(+) / \mathrm{CTC}(+)$. Moreover, $13(26.5 \%)$ of the initially DTC $(+) / \mathrm{CTC}(+)$ patients, as well as 8 $(27.5 \%)$ of the initially DTC $(-) / C T C(-)$ patients, had detectable occult tumour cells either in the bone marrow or peripheral blood after completion of adjuvant chemotherapy.
Clinical relapses and disease-related deaths according to the detection of CK-19 mRNA-positive CTCs and DTCs

After a median follow-up period of 59.0 months (range, 13-95), 37 (22.4\%) patients presented a local and/or distant relapse and 20 $(12.1 \%)$ died because of disease progression. In the group of patients with CK-19 mRNA-positive CTCs $(\mathrm{CTC}(+)$ group) before the initiation of chemotherapy, $25(27.5 \%)$ out of 91 relapsed, compared with $12(16.2 \%)$ out of 74 patients in the CTC(-) group (Table 3; $P=0.081$ ). Among the 95 women with CK-19 mRNA-positive DTCs (DTC $(+)$ group), $26(27.4 \%)$ relapsed compared with 11 $(15.7 \%)$ among 70 patients in the DTC $(-)$ group (Table 3; $P=0.105)$. 
When analysing survival data according to CTC status before chemotherapy, $15(16.5 \%)$ out of $91 \mathrm{CTC}(+)$ patients died compared with $5(6.8 \%)$ out of $74 \mathrm{CTC}(-)$ patients (Table 3). The Kaplan-Meier survival analysis showed a significantly reduced probability for OS for patients in the CTC $(+)$ group compared with that in the CTC $(-)$ group (log-rank test, $P=0.024$; Figure $2 \mathrm{~A}$ ). Similar results were observed for OS according to DTC status before chemotherapy. Specifically, $17(17.9 \%)$ out of 95 patients in the DTC $(+)$ group died compared with $3(4.3 \%)$ out of 70 patients in the DTC $(-)$ group (log-rank test, $P=0.015$; Figure $2 \mathrm{~B}$ ).

In the group of 162 patients with peripheral blood samples available after the completion of therapy, $22(27.8 \%)$ out of 79 and
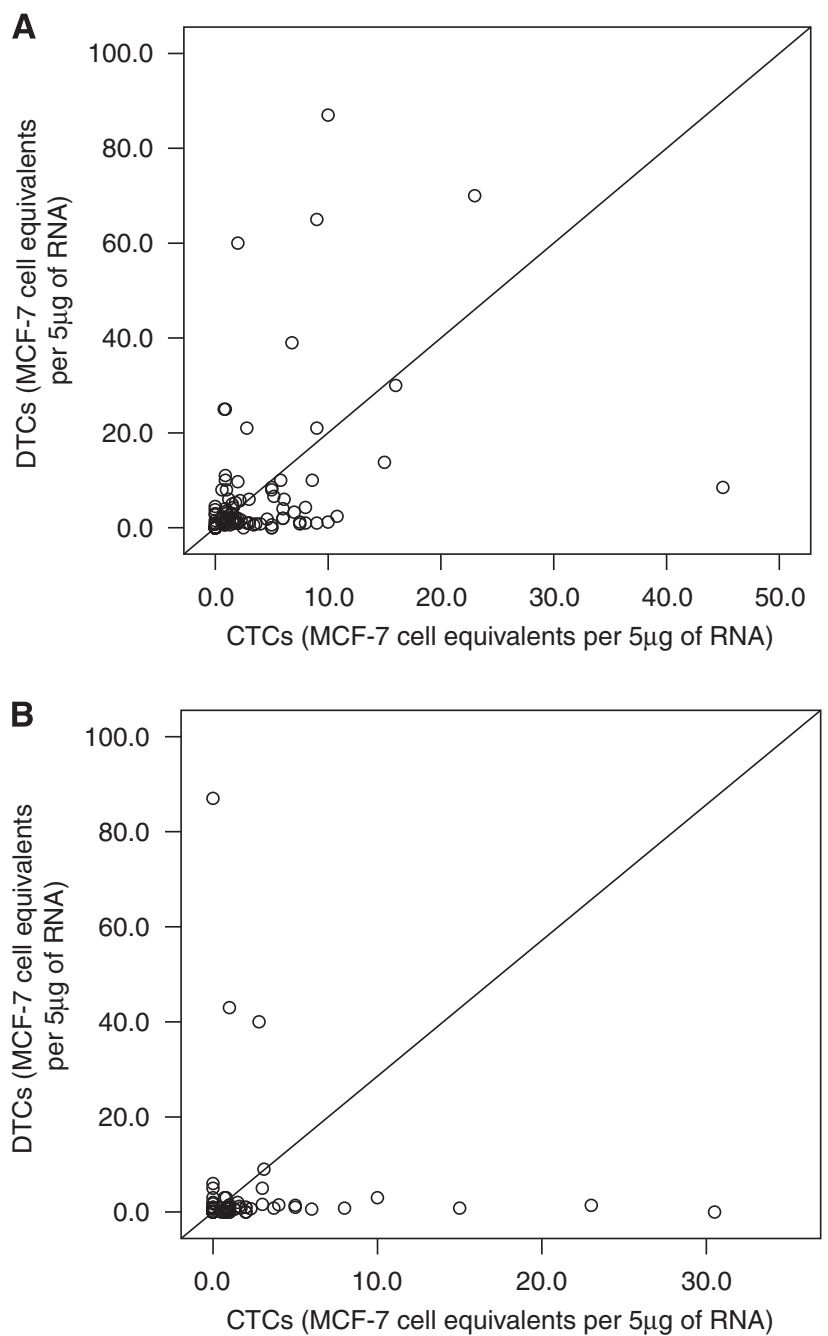

Figure I Correlation between the presence of CTCs and DTCs before initiation (A) and after the completion (B) of adjuvant chemotherapy.
15 (18.1\%) out of 83 relapsed in $\mathrm{CTC}(+)$ and $\mathrm{CTC}(-)$ groups, respectively (Table $3 ; P=0.057$ ). Among the group of 84 patients with a bone marrow sample obtained after chemotherapy, the number of relapses was $11(25.6 \%)$ out of 43 and $6(14.6 \%)$ out of 41 patients $(P=0.162)$ in the $\mathrm{DTC}(+)$ and $\mathrm{DTC}(-)$ groups, respectively. No significant difference was observed in patients' survival according to the detection of CTCs $(P=0.128)$ or DTCs $(P=0.302)$ after chemotherapy (Table 3$)$.

\section{Clinical outcome according to the concomitant detection of CK-19 mRNA-positive CTCs and DTCs}

The outcome of patients according to the concomitant detection of CK-19 mRNA-positive CTCs and DTCs before the initiation of chemotherapy is presented in Table 4 . The incidence of relapses was 27.3 and $14.9 \%$ in patients of DTC $(+) / C T C(+)$ and DTC $(-) /$ $\mathrm{CTC}(-)$ groups before chemotherapy, respectively (Table 4; $P=0.066) ; 3(30 \%)$ additional relapses occurred among 10 patients who had detectable DTCs or CTCs (group 'other combinations'; Table 4). A total of $15(17 \%)$ deaths occurred in patients of the DTC $(+) / C T C(+)$ group compared with $3(4.5 \%)$ in the subgroup of patients with a DTC $(-) / C T C(-)$ status before chemotherapy. The Kaplan-Meier survival analysis showed a significantly longer OS in patients of the DTC $(-) / C T C(-)$ group compared with those of the $\mathrm{DTC}(+) / \mathrm{CTC}(+)$ group (log-rank test, $P=0.016$; Figure $3 \mathrm{~A})$. Moreover, OS was significantly longer in patients with a DTC $(-) / C T C(-)$ status compared with those with at least one positive result designated as 'other combinations' (log-rank test, $P=0.021$; Figure $3 \mathrm{~B})$. A total of $6(22.1 \%)$ deaths occurred in the group of patients who had persistently positive peripheral blood and bone marrow, both before and after chemotherapy; conversely, no deaths were observed in patients without detectable CK-19 mRNA-positive CTCs and DTCs, either before or after the completion of chemotherapy (log-rank test, $P=0.036$ ).

\section{Univariate and multivariate analysis}

As shown in Table 5, tumour size, histological grade and $\geqslant 4$ involved axillary lymph nodes were significantly associated with decreased DFS in univariate analysis. Factors associated with decreased OS were the detection of CTCs, DTCs, as well as the simultaneous detection of CTCs and DTCs before chemotherapy.

A multivariate analysis including factors that were most significantly associated with DFS and OS in the univariate analysis showed that tumour size $(P=0.031)$ and the involvement of $\geqslant 4$ axillary lymph nodes $(P=0.036)$ were independent factors associated with decreased DFS (Table 6), whereas histological grade $(P=0.022)$, PR negativity $(P=0.013)$, and the detection of DTCs before chemotherapy $(P=0.032)$ were independently associated with decreased OS (Table 6). Owing to the significant correlation observed between the detection of CTCs and DTCs, the CTC status before chemotherapy was not included in the multivariate analysis.

Table 2 Concordance of CTCs and DTCs

\begin{tabular}{|c|c|c|c|c|c|}
\hline \multicolumn{3}{|c|}{ Pre-chemotherapy $(n=165)$} & \multicolumn{3}{|c|}{ Post-chemotherapy $(n=84)$} \\
\hline$n$ & $\begin{array}{c}\text { CTC(+) } \\
91 \text { (55.2\%) }\end{array}$ & $\begin{array}{c}\text { CTC(-) } \\
74(44.8 \%)\end{array}$ & $n$ & $\begin{array}{c}\text { CTC(+) } \\
44(52.4 \%)\end{array}$ & $\begin{array}{c}\text { CTC(-) } \\
40(47.6 \%)\end{array}$ \\
\hline $\begin{array}{l}\text { DTC }(+) \\
95(57.6 \%)\end{array}$ & 88 (53.3\%) & 7 (4.2\%) & $\begin{array}{c}\text { DTC (+) } \\
43(51.2 \%)\end{array}$ & 32 (38.1\%) & II (13.1\%) \\
\hline $\begin{array}{l}\text { DTC }(-) \\
70(42.4 \%)\end{array}$ & $3(1.8 \%)$ & 67 (40.6\%) & $\begin{array}{l}\text { DTC }(-) \\
41(48.8 \%)\end{array}$ & $12(14.2 \%)$ & $29(34.5 \%)$ \\
\hline
\end{tabular}

$\mathrm{CTC}=$ circulating tumour cell; DTC $=$ disseminated tumour cell. 
Table 3 Incidence of relapses and disease-related deaths according to the detection of CK-19 mRNA(+) CTCs and DTCs as considered separately

\begin{tabular}{|c|c|c|c|c|c|}
\hline & & $\begin{array}{c}\text { Relapse } \\
n(\%)\end{array}$ & $P$-value & $\begin{array}{l}\text { Death } \\
n(\%)\end{array}$ & $P$-value \\
\hline \multicolumn{6}{|l|}{ Pre-chemotherapy } \\
\hline DTC status $(n=165)$ & $\begin{array}{l}\operatorname{DTC}(+)(n=95) \\
\operatorname{DTC}(-)(n=70)\end{array}$ & $\begin{array}{l}26(27.4) \\
11(15.7)\end{array}$ & 0.105 & $\begin{array}{c}17(17.9) \\
3(4.3)\end{array}$ & 0.015 \\
\hline DTC status $(n=84)$ & $\begin{array}{l}\operatorname{DTC}(+)(n=43) \\
\operatorname{DTC}(-)(n=41)\end{array}$ & $\begin{array}{r}11(25.6) \\
6(14.6)\end{array}$ & 0.162 & $\begin{array}{l}7(16.3) \\
5(12.2)\end{array}$ & 0.302 \\
\hline
\end{tabular}

CK-19= cytokeratin-19; CTC = circulating tumour cell; DTC = disseminated tumour cell. Significant $P$-values are shown in bold.
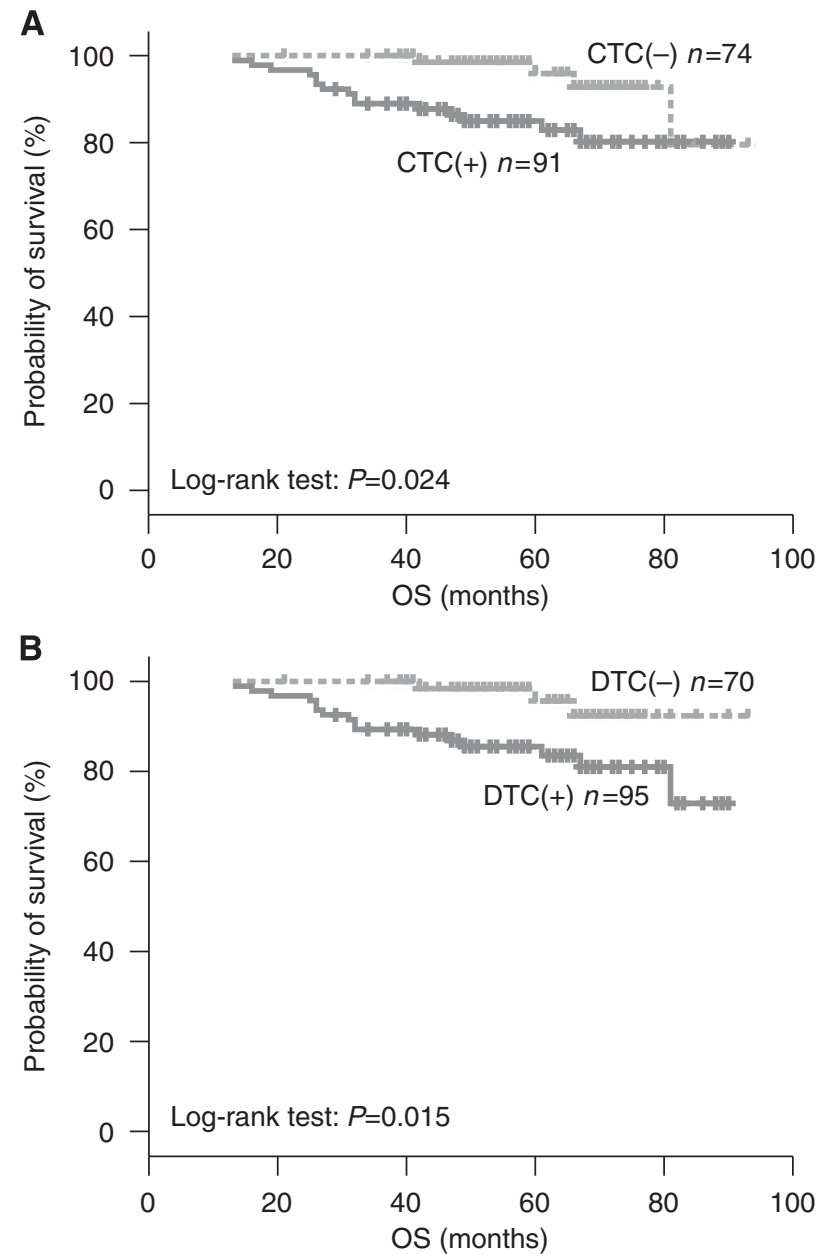

Figure 2 Overall survival curves of patients with early breast cancer according to the detection of $\operatorname{CTCS}(\mathbf{A})$ and DTCs (B) before chemotherapy.

\section{DISCUSSION}

The data presented in this study show that there is a significant concordance between the detection of CK-19 mRNA-positive cells detected in the peripheral blood (CTCs) and in bone marrow (DTCs) of patients with early breast cancer, both before initiation
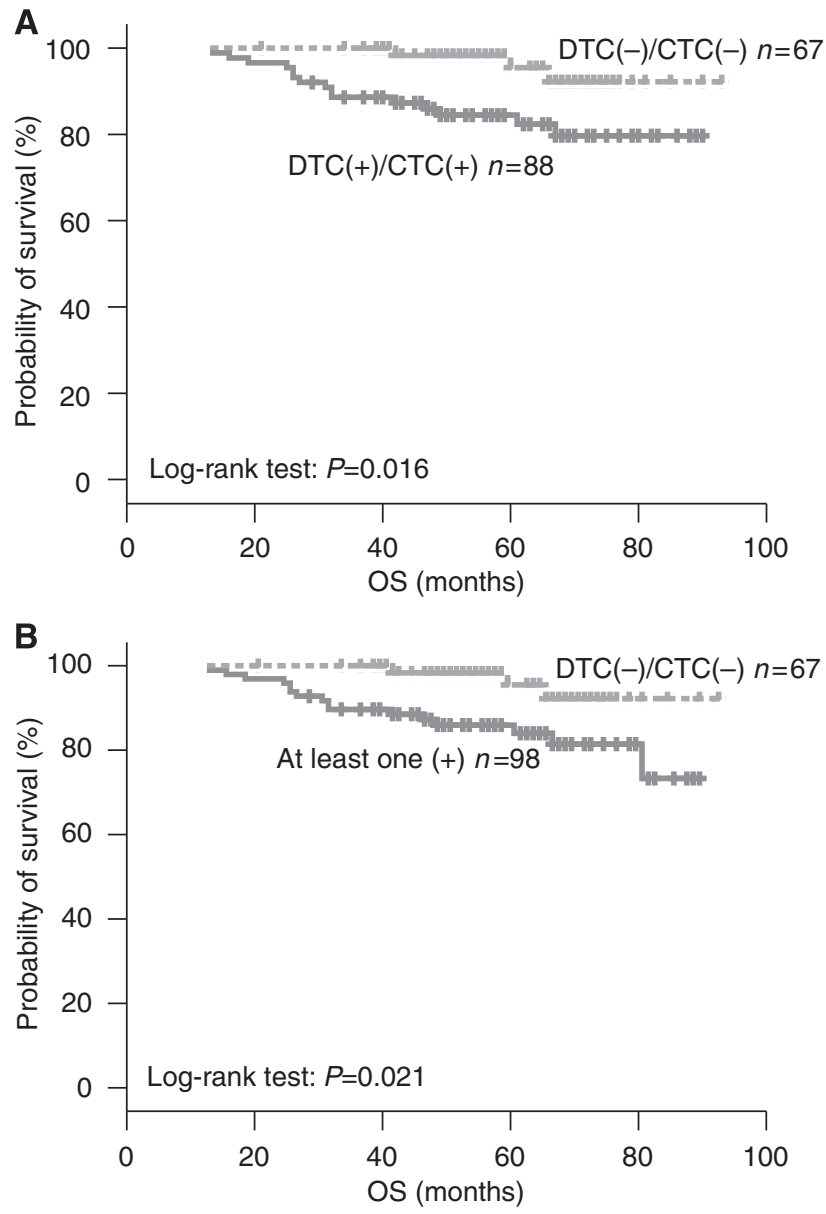

Figure 3 Overall survival curves of patients with early breast cancer according to the concomitant detection of CTCs and DTCs. (A) Both positive vs both negative. (B) Both negative vs at least one positive ('other combinations').

and after completion of adjuvant chemotherapy. In addition, it was shown that the detection of CTCs or DTCs before chemotherapy was associated with decreased survival of patients.

Using a quantitative RT-PCR for detecting CK-19 mRNApositive cells, we observed a concordance rate of 93.9 and $72.6 \%$ between peripheral blood and bone marrow samples obtained 
CK-19 mRNA + CTCs and DTCs in BC

A Daskalaki et al

Table 4 Incidence of relapses and disease-related deaths according to the concomitant detection of CK-19 mRNA(+) CTCs and DTCs prechemotherapy

\begin{tabular}{|c|c|c|c|c|c|c|}
\hline DTC/CTC status & \multicolumn{3}{|c|}{ Clinical relapses } & \multicolumn{3}{|c|}{ Deaths } \\
\hline $\begin{array}{l}\operatorname{CTC}(+) / \operatorname{DTC}(+)(n=88) \\
\operatorname{CTC}(-) / \operatorname{DTC}(-)(n=67) \\
\text { Other combinations }{ }^{\mathrm{a}}(n=10)\end{array}$ & $\begin{array}{r}24(27.3 \%) \\
10(14.9 \%) \\
3(30.0 \%)\end{array}$ & $\begin{array}{r}64(72.7 \%) \\
57(85.1 \%) \\
7(70.0 \%)\end{array}$ & 0.066 & $\begin{aligned} 15 & (17.0 \%) \\
3 & (4.5 \%) \\
2 & (20.0 \%)\end{aligned}$ & $\begin{array}{l}73(83.0 \%) \\
64(95.5 \%) \\
16(80.0 \%)\end{array}$ & 0.016 \\
\hline
\end{tabular}

CK-19 = cytokeratin-19; CTC $=$ circulating tumour cell; DTC $=$ disseminated tumour cell. ${ }^{a}(\mathrm{CTC}(+) / \mathrm{DTC}(-)$ or $\mathrm{CTC}(-) / \mathrm{DTC}(+))$. Significant $P$-values are shown in bold.

Table 5 Predictive and prognostic factors by univariate analyses (unadjusted relative risk) for DFS and OS

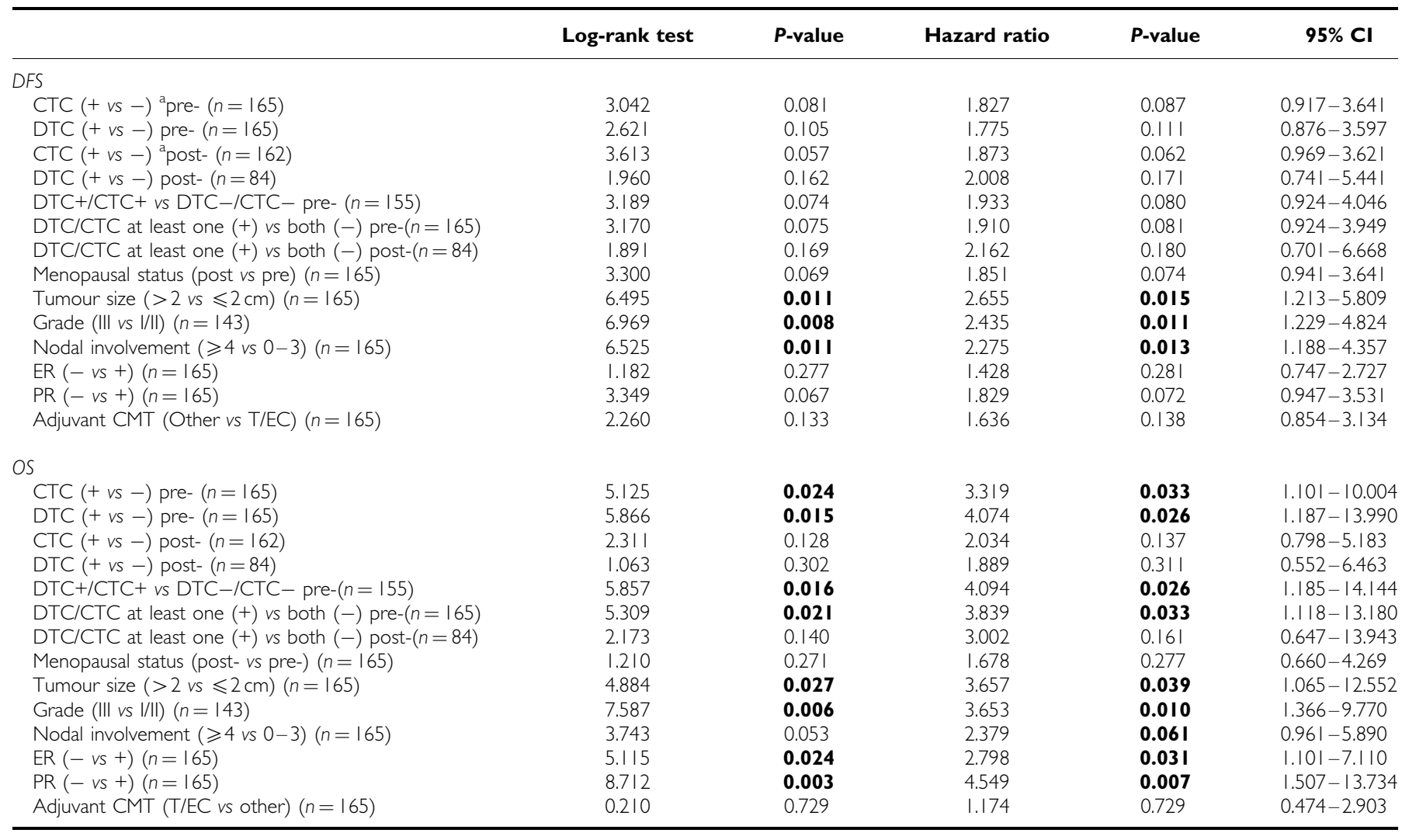

- = negative; += positive; $\mathrm{Cl}=$ confidence interval; $\mathrm{CTC}=$ circulating tumour cell; $\mathrm{DFS}=$ disease-free survival; $\mathrm{DTC}=$ disseminated tumour cell; $\mathrm{ER}=$ oestrogen receptor; $\mathrm{OS}=$ overall survival; $\mathrm{PR}=$ progesterone receptor. ${ }^{\text {a }}$ pre- and post- refer to the pre- and post-chemotherapy values CTC and DTC. Significant $P$-values are shown in bold.

Table 6 Multivariate analysis for DFS and OS

\begin{tabular}{lccc}
\hline Parameter & Hazard ratio & $\mathbf{9 5 \%} \mathbf{C l}$ & P-value \\
\hline DFS & & & \\
Tumour size $(>2$ vs $\leqslant 2 \mathrm{~cm})$ & 2.391 & $1.085-5.273$ & $\mathbf{0 . 0 3 ~ I}$ \\
Lymph nodes $(\geqslant 4$ vs $0-3)$ & 2.014 & $1.045-3.88 \mid$ & $\mathbf{0 . 0 3 6}$ \\
OS & & & \\
Histology grade (III vs I/II) & 3.220 & $1.184-8.762$ & $\mathbf{0 . 0 2 2}$ \\
PR $(-$ vs + ) & 4.061 & $1.337-12.332$ & $\mathbf{0 . 0 1 3}$ \\
DTC (+ vs - ) pre-chemotherapy & 3.859 & $0.119-13.303$ & $\mathbf{0 . 0 3 2}$ \\
\hline
\end{tabular}

$\mathrm{Cl}=$ confidence interval; DFS = disease-free survival; DTC = disseminated tumour cell; $\mathrm{OS}=$ overall survival; $\mathrm{PR}=$ progesterone receptor. Significant $P$-values are shown in bold.

before initiation and after completion of adjuvant chemotherapy, respectively, in patients with early breast cancer. Similar observations have been reported by other investigators who evaluated the presence of CK-positive cells in the peripheral blood and bone marrow using immunocytochemical assays (Witzig et al, 2002; Pierga et al, 2004; Muller et al, 2005; Wiedswang et al, 2006). In a previous report from our group, we reported a weaker correlation between the detection of CK-19 mRNA expression in blood and in the bone marrow in a smaller series of patients with early breast cancer using a qualitative nested RT-PCR assay (Stathopoulou et al, 2002). Differences in the assays used could account for these discrepancies. Indeed, Schoenfeld et al (1997) have reported that the concordance between blood and bone marrow samples for occult tumour cell detection was only $6 \%$ by immunocytochemistry and $27 \%$ by RT-PCR.

The lack of a complete overlap between the presence of CK-19 mRNA-positive CTCs and DTCs either before (Ismail et al, 2004; Pierga et al, 2004; Muller et al, 2005; Wiedswang et al, 2006) or after chemotherapy (Slade et al, 2009) could be related to the fact that occult tumour cells are rare events and therefore their evaluation is greatly influenced by sampling variability. In addition, it has been suggested that blood represents a temporary compartment for 
disseminated cells (Muller et al, 2005), whereas only a subpopulation of CTCs can settle in distant organs such as the bone marrow (Muller et al, 2005). Nevertheless, the high concordance observed between CTC and DTC detection in our study favours the hypothesis that there is a continuous circulation and exchange of epithelial cells between bone marrow and peripheral blood.

The high detection rate of occult tumour cells in both peripheral blood and bone marrow observed in the current study is in overt contrast with previous studies reporting low detection rates using immunocytochemical assays (Ismail et al, 2004; Pierga et al, 2004; Muller et al, 2005; Wiedswang et al, 2006; Benoy et al, 2006) and should be attributed to the high sensitivity and specificity of the quantitative RT-PCR assay used for the detection of minimal residual disease (Stathopoulou et al, 2003). Moreover, it is interesting to note that only $10 \%$ of 1767 patients with early disease had more than one CTC per $23 \mathrm{ml}$ of peripheral blood when tested with the new automated Cell Search System (Rack et al, 2007, 2008).

This analysis also shows that CK-19 mRNA-positive tumour cells persist in the blood and/or bone marrow of patients with early breast cancer despite the administration of adjuvant chemotherapy. Indeed, 63.7 and $62.2 \%$ of patients in the CTC $(+)$ and DTC $(+)$ groups before the initiation of chemotherapy, respectively, had occult tumour cells detected in their blood or bone marrow after chemotherapy. In addition, 28.4 and $32.2 \%$ of patients without detectable CTCs or DTCs, before chemotherapy, respectively, presented with CK-19 mRNA-positive cells after the completion of adjuvant chemotherapy. This observation suggests that chemoresistant cells in patients identified as DTC $(-)$ or/and CTC (-) because of a low tumour load that is undetectable by the assay could proliferate during the administration of adjuvant chemotherapy and reach the detection limit after the end of treatment. Moreover, the increase in discordance between the detection of CTCs and DTCs after chemotherapy suggests that CTCs and DTCs represent biologically and genetically different cells with a variable sensitivity to chemotherapy.

The above observations point to the presence of subpopulations of CTCs or/and DTCs that bear an inherent resistance to the chemotherapy regimen used as adjuvant treatment. The presence of chemoresistant CTCs or DTCs has been previously described (Braun et al, 2000a; Xenidis et al, 2003, 2009) and attributed to the low proliferative capacity of these cells (Pantel et al, 1993; Muller et al, 2005). Therefore, it could be hypothesised that the detection of occult tumour cells after the completion of adjuvant chemotherapy could be used as a surrogate marker for the efficacy of the adjuvant treatment used.

\section{REFERENCES}

Altman GD (1991) Practical Statistics for Medical Research. Chapman and Hall: London, UK

Armitage P, Berry G (1994) Statistical Methods in Medical Research (3rd edn). Blackwell Scientific: Oxford, UK

Benoy IH, Elst H, Philips M, Wuyts H, Van Dam P, Scharpe S, Van Marck E, Vermeulen PB, Dirix LY (2006) Real-time RT-PCR detection of disseminated tumour cells in bone marrow has superior prognostic significance in comparison with circulating tumour cells in patients with breast cancer. Br J Cancer 94: 672-680

Braun S, Kentenich C, Janni W, Hepp F, de Waal J, Willgeroth F, Sommer H, Pantel K (2000a) Lack of effect of adjuvant chemotherapy on the elimination of single dormant tumor cells in bone marrow of high-risk breast cancer patients. J Clin Oncol 18: 80-86

Braun S, Naume B (2005) Circulating and disseminated tumor cells. J Clin Oncol 23: $1623-1626$

Braun S, Pantel K, Muller P, Janni W, Hepp F, Kentenich CR, Gastroph S, Wischnik A, Dimpfl T, Kindermann G, Riethmuller G, Schlimok G (2000b) Cytokeratin-positive cells in the bone marrow and survival of patients with stage I, II, or III breast cancer. N Engl J Med 342: 525-533

Coombes RC, Kilburn LS, Snowdon CF, Paridaens R, Coleman RE, Jones SE, Jassem J, Van de Velde CJ, Delozier T, Alvarez I,
Previous reports evaluating the prognostic significance of disseminated tumour cells in blood and bone marrow concluded that the detection of CTCs is prognostically inferior to the detection of DTCs (Pierga et al, 2004; Benoy et al, 2006; Wiedswang et al, 2006). In this study, the presence of CK-19 mRNA-positive CTCs and DTCs before the initiation of adjuvant chemotherapy was predictive for decreased OS. Moreover, in the multivariate analysis, the detection of DTCs was an independent prognostic factor associated with a significantly higher risk of death.

Several reports have shown that the persistence of occult tumour cells in the bone marrow (Wiedswang et al, 2004; Janni et al, 2005) or peripheral blood (Xenidis et al, 2003, 2007, 2009) after adjuvant chemotherapy or during follow-up is associated with an adverse clinical outcome. In this study, the detection of CTCs and/or DTCs after chemotherapy was not associated with increased risk for relapse or death. Further prospective studies including a larger number of patients are needed to clarify which is the most relevant time point for the evaluation of minimal residual disease before or after adjuvant chemotherapy. Moreover, the reproducibility and stability of the assays used should also be evaluated in a routine clinical setting.

In conclusion, the results of this study indicate that the detection of CK-19 mRNA-positive DTCs and CTCs both before and after chemotherapy is correlated in patients with early-stage breast cancer. The determination of the CTC status was shown to convey prognostic information that was of comparable clinical relevance with that of DTC status. However, for convenience, the detection of CTCs could be used as an alternative to bone marrow for the identification of occult breast cancer cells and for monitoring minimal residual disease. This is of particular interest in the light of the results of recent trials, indicating that sequential treatment during the disease-free period may improve OS in breast cancer (Coombes et al, 2007; Kaufmann et al, 2007). Conceivably, secondary adjuvant treatment could be administered in patients selected on the basis of persisting CTCs. However, this should be tested in prospective clinical trials.

\section{ACKNOWLEDGEMENTS}

This work was partly supported by research grants from Pfizer Pharmaceuticals and the Cretan Association for Biomedical Research (CABR).
Del Mastro L, Ortmann O, Diedrich K, Coates AS, Bajetta E, Holmberg SB, Dodwell D, Mickiewicz E, Andersen J, Lonning PE, Cocconi G, Forbes J, Castiglione $M$, Stuart N, Stewart A, Fallowfield LJ, Bertelli G, Hall E, Bogle RG, Carpentieri M, Colajori E, Subar M, Ireland E, Bliss JM (2007) Survival and safety of exemestane versus tamoxifen after 2-3 years' tamoxifen treatment (Intergroup Exemestane Study): a randomised controlled trial. Lancet 369: $559-570$

Collett D (2003) Modelling Binary Data. Chapman and Hall/CRC: London, UK

Cox DR (1970) The Analysis of Binary Data. Methuen: London, UK Cristofanilli M, Budd GT, Ellis MJ, Stopeck A, Matera J, Miller MC, Reuben JM, Doyle GV, Allard WJ, Terstappen LW, Hayes DF (2004) Circulating tumor cells, disease progression, and survival in metastatic breast cancer. $N$ Engl J Med 351: 781 -791

Dowlatshahi K, Fan M, Snider HC, Habib FA (1997) Lymph node micrometastases from breast carcinoma: reviewing the dilemma. Cancer 80: $1188-1197$

EBCTC Group (1998) Polychemotherapy for early breast cancer: an overview of the randomised trials. Early Breast Cancer Trialists' Collaborative Group. Lancet 352: $930-942$ 
EBCTC Group (2005) Effects of chemotherapy and hormonal therapy for early breast cancer on recurrence and 15-year survival: an overview of the randomised trials. Lancet 365: 1687-1717

Giatromanolaki A, Koukourakis MI, Kakolyris S, Mavroudis D, Kouroussis C, Mavroudi C, Perraki M, Sivridis E, Georgoulias V (2004) Assessment of highly angiogenic and disseminated in the peripheral blood disease in breast cancer patients predicts for resistance to adjuvant chemotherapy and early relapse. Int J Cancer 108: 620-627

Ignatiadis M, Xenidis N, Perraki M, Apostolaki S, Politaki E, Kafousi M, Stathopoulos EN, Stathopoulou A, Lianidou E, Chlouverakis G, Sotiriou C, Georgoulias V, Mavroudis D (2007) Different prognostic value of cytokeratin-19 mRNA positive circulating tumor cells according to estrogen receptor and HER2 status in early-stage breast cancer. J Clin Oncol 25: 5194-5202

Ismail MS, Wynendaele W, Aerts JL, Paridaens R, Gaafar R, Shakankiry N, Khaled HM, Christiaens MR, Wildiers H, Omar S, Vandekerckhove P, Van Oosterom AT (2004) Detection of micrometastatic disease and monitoring of perioperative tumor cell dissemination in primary operable breast cancer patients using real-time quantitative reverse transcription-PCR. Clin Cancer Res 10: 196-201

Janni W, Rack B, Schindlbeck C, Strobl B, Rjosk D, Braun S, Sommer H, Pantel K, Gerber B, Friese K (2005) The persistence of isolated tumor cells in bone marrow from patients with breast carcinoma predicts an increased risk for recurrence. Cancer 103: 884-891

Kaufmann M, Jonat W, Hilfrich J, Eidtmann H, Gademann G, Zuna I, von Minckwitz G (2007) Improved overall survival in postmenopausal women with early breast cancer after anastrozole initiated after treatment with tamoxifen compared with continued tamoxifen: the ARNO 95 Study. J Clin Oncol 25: 2664-2670

Mansi JL, Gogas H, Bliss JM, Gazet JC, Berger U, Coombes RC (1999) Outcome of primary-breast-cancer patients with micrometastases: a long-term follow-up study. Lancet 354: 197-202

McShane LM, Altman DG, Sauerbrei W, Taube SE, Gion M, Clark GM (2005) Reporting recommendations for tumor marker prognostic studies (REMARK). J Natl Cancer Inst 97: 1180 - 1184

Muller V, Stahmann N, Riethdorf S, Rau T, Zabel T, Goetz A, Janicke F, Pantel K (2005) Circulating tumor cells in breast cancer: correlation to bone marrow micrometastases, heterogeneous response to systemic therapy and low proliferative activity. Clin Cancer Res 11: 3678-3685

Pantel K, Cote RJ, Fodstad O (1999) Detection and clinical importance of micrometastatic disease. J Natl Cancer Inst 91: 1113-1124

Pantel K, Schlimok G, Braun S, Kutter D, Lindemann F, Schaller G, Funke I, Izbicki JR, Riethmuller G (1993) Differential expression of proliferationassociated molecules in individual micrometastatic carcinoma cells. J Natl Cancer Inst 85: 1419-1424

Pierga JY, Bonneton C, Vincent-Salomon A, de Cremoux P, Nos C, Blin N, Pouillart P, Thiery JP, Magdelenat H (2004) Clinical significance of immunocytochemical detection of tumor cells using digital microscopy in peripheral blood and bone marrow of breast cancer patients. Clin Cancer Res 10: $1392-1400$

Rack BK, Schindlbeck C, Hofmann S, Schneeweiss A., Rezai M, Beckmann M, Pantel K, Schneider A, Sommer H, Janni W (2007) Circulating tumor cells (CTCs) in peripheral blood of primary breast cancer patients. J Clin Oncol 25: 18S; (abstract no. 10595)

Rack BK, Schindlbeck C, Hofmann S, Schneeweiss A, Hilfrich J, Lorenz R, Beckmann MW, Pantel K, Lichtenegger W, Sommer HL, Janni WJ (2008) Prognostic relevance of circulating tumor cells (CTCs) in peripheral blood of breast cancer patients before and after adjuvant chemotherapy: The German SUCCESS-Trial. J Clin Oncol 26: 20S; (abstract no. 503)

Schoenfeld A, Kruger KH, Gomm J, Sinnett HD, Gazet JC, Sacks N, Bender HG, Luqmani Y, Coombes RC (1997) The detection of micrometastases in the peripheral blood and bone marrow of patients with breast cancer using immunohistochemistry and reverse transcriptase polymerase chain reaction for keratin 19. Eur J Cancer 33: 854-861
Slade MJ, Payne R, Riethdorf S, Ward B, Zaidi SA, Stebbing J, Palmieri C, Sinnett HD, Kulinskaya E, Pitfield T, McCormack RT, Pantel K, Coombes RC (2009) Comparison of bone marrow, disseminated tumour cells and blood-circulating tumour cells in breast cancer patients after primary treatment. Br J Cancer 100: 160 - 166

Slade MJ, Smith BM, Sinnett HD, Cross NC, Coombes RC (1999) Quantitative polymerase chain reaction for the detection of micrometastases in patients with breast cancer. J Clin Oncol 17: 870-879

Stathopoulos EN, Sanidas E, Kafousi M, Mavroudis D, Askoxylakis J, Bozionelou V, Perraki M, Tsiftsis D, Georgoulias V (2005) Detection of CK-19 mRNA-positive cells in the peripheral blood of breast cancer patients with histologically and immunohistochemically negative axillary lymph nodes. Ann Oncol 16: $240-246$

Stathopoulou A, Gizi A, Perraki M, Apostolaki S, Malamos N, Mavroudis D, Georgoulias V, Lianidou ES (2003) Real-time quantification of CK-19 mRNA-positive cells in peripheral blood of breast cancer patients using the LightCycler system. Clin Cancer Res 9: 5145-5151

Stathopoulou A, Vlachonikolis I, Mavroudis D, Perraki M, Kouroussis C, Apostolaki S, Malamos N, Kakolyris S, Kotsakis A, Xenidis N, Reppa D, Georgoulias V (2002) Molecular detection of cytokeratin-19positive cells in the peripheral blood of patients with operable breast cancer: evaluation of their prognostic significance. J Clin Oncol 20: $3404-3412$

Wiedswang G, Borgen E, Karesen R, Kvalheim G, Nesland JM, Qvist H, Schlichting E, Sauer T, Janbu J, Harbitz T, Naume B (2003) Detection of isolated tumor cells in bone marrow is an independent prognostic factor in breast cancer. J Clin Oncol 21: 3469-3478

Wiedswang G, Borgen E, Karesen R, Qvist H, Janbu J, Kvalheim G, Nesland JM, Naume B (2004) Isolated tumor cells in bone marrow three years after diagnosis in disease-free breast cancer patients predict unfavorable clinical outcome. Clin Cancer Res 10: $5342-5348$

Wiedswang G, Borgen E, Schirmer C, Karesen R, Kvalheim G, Nesland JM, Naume B (2006) Comparison of the clinical significance of occult tumor cells in blood and bone marrow in breast cancer. Int J Cancer 118: $2013-2019$

Witzig TE, Bossy B, Kimlinger T, Roche PC, Ingle JN, Grant C, Donohue J, Suman VJ, Harrington D, Torre-Bueno J, Bauer KD (2002) Detection of circulating cytokeratin-positive cells in the blood of breast cancer patients using immunomagnetic enrichment and digital microscopy. Clin Cancer Res 8: 1085 - 1091

Xenidis N, Ignatiadis M, Apostolaki S, Perraki M, Kalbakis K, Agelaki S, Stathopoulos EN, Chlouverakis G, Lianidou E, Kakolyris S, Georgoulias V, Mavroudis D (2009) Cytokeratin-19 mRNA-positive circulating tumor cells after adjuvant chemotherapy in patients with early breast cancer. J Clin Oncol 27: 2177-2184

Xenidis N, Markos V, Apostolaki S, Perraki M, Pallis A, Sfakiotaki G, Papadatos-Pastos D, Kalmanti L, Kafousi M, Stathopoulos E, Kakolyris S, Mavroudis D, Georgoulias V (2007) Clinical relevance of circulating CK-19 mRNA-positive cells detected during the adjuvant tamoxifen treatment in patients with early breast cancer. Ann Oncol 18: $1623-1631$

Xenidis N, Perraki M, Kafousi M, Apostolaki S, Bolonaki I, Stathopoulou A, Kalbakis K, Androulakis N, Kouroussis C, Pallis T, Christophylakis C, Argyraki K, Lianidou ES, Stathopoulos S, Georgoulias V, Mavroudis D (2006) Predictive and prognostic value of peripheral blood cytokeratin-19 mRNA-positive cells detected by real-time polymerase chain reaction in node-negative breast cancer patients. J Clin Oncol 24: $3756-3762$

Xenidis N, Vlachonikolis I, Mavroudis D, Perraki M, Stathopoulou A, Malamos N, Kouroussis C, Kakolyris S, Apostolaki S, Vardakis N, Lianidou E, Georgoulias V (2003) Peripheral blood circulating cytokeratin-19 mRNA-positive cells after the completion of adjuvant chemotherapy in patients with operable breast cancer. Ann Oncol 14: $849-855$ 